Life Sciences Division

\title{
TREATMENT OF PLUTONIUM- AND URANIUM-CONTAMINATED OIL FROM ROCKY FLATS ENVIRONMENTAL TECHNOLOGY SITE
}

\author{
K. T. Klasson
}

\section{Topical Report}

\section{Date Published-November 2002}

\begin{abstract}
"The submitted manuscript has been authored by a contractor of the U.S. Government under contract No. DE-AC05-00OR22725. Accordingly, the U.S. Government retains a nonexclusive, royalty-free license to publish or

reproduce the published form of the contribution, or allow others to do so, for U.S. Government purposes."
\end{abstract}

Prepared by

\section{OAK RIDGE NATIONAL LABORATORY}

Oak Ridge, Tennessee 37831

managed by

UT-BATTELLE, LLC

for the

\section{U.S. DEPARTMENT OF ENERGY}

under contract DE-AC05-00OR22725 


\title{
Treatment of Plutonium- and Uranium-Contaminated Oil from Rocky Flats Environmental Technology Site
}

\author{
K. Thomas Klasson \\ Oak Ridge National Laboratory \\ Oak Ridge, Tennessee 37831-6226 \\ (865) 574-6813, klassonkt@ornl.gov
}

\section{Introduction}

A removal method for plutonium and uranium has been tested at the Rocky Flats Environmental Technology Site (RFETS). This alternative treatment technology is applicable to U.S. Department of Energy (DOE) organics (mainly used pump oil) contaminated with actinides. In our studies, greater than $70 \%$ removal of the actinides was achieved.

The technology is based on contacting the oil with a sorbent powder consisting of a surface modified mesoporous

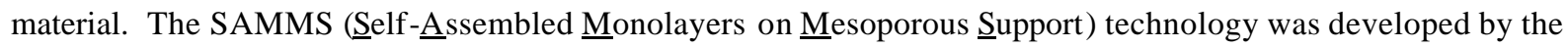
Pacific Northwest National Laboratory for removal and stabilization of RCRA (i.e., lead, mercury, cadmium, silver, etc.) and actinides in water and for removal of mercury from organic solvents [1,2]. The SAMMS material is based on self-assembly of functionalized monolayers on mesoporous oxide surfaces. The unique mesoporous oxide support provides a high surface area, thereby enhancing the metal-loading capacity. The testing described in this report was conducted on a small scale but larger-scale testing of the technology has been performed on mercurycontaminated oil without difficulty [3].

\section{Materials and Methods}

The SAMMS material was kindly provided by Rich Hallen and Glen Fryxell at Pacific Northwest National Laboratory (PNNL) and is described as a surface-modified material with propyl phosphonate functional groups. The starting material was a high silica material (MCM-41) from ExxonMobil and the functional groups were then attached to this material. It was anticipated that the distribution coefficient for Pu on the material was $20,000 \mathrm{~L} / \mathrm{kg}$ (liquid/sorbent).

The experiments were performed at the Rocky Flats Environmental Technology Site under the direction of Mike Rivera using the equipment shown in Figure 1, which consisted of polypropylene centrifuge tubes (50 mL capacity), a rotary mixer, disposable filters $(0.8 \mu \mathrm{m}$ pore size $)$, and a handheld vacuum pump. In the study, different amounts of SAMMS were mixed with $50 \mathrm{~mL}$ of oil (from waste bottle 20263) by hand for a few minutes then placed on the rotary mixer for duration of the day $(8 \mathrm{~h})$. The mixing was halted at the end of the day but continued the next day 
and the day after that for a total mixing time of $24 \mathrm{~h}$. After the mixing, the oil was vacuum-filtered and the filtrate was submitted for analysis using standard radiochemical analytical procedures. The waste pump oil initially contained $0.0798 \mathrm{~g}$ plutonium, $0.192 \mathrm{~g}$ uranium, and $1.18 \cdot 10^{-5} \mathrm{~g}$ americium per liter.

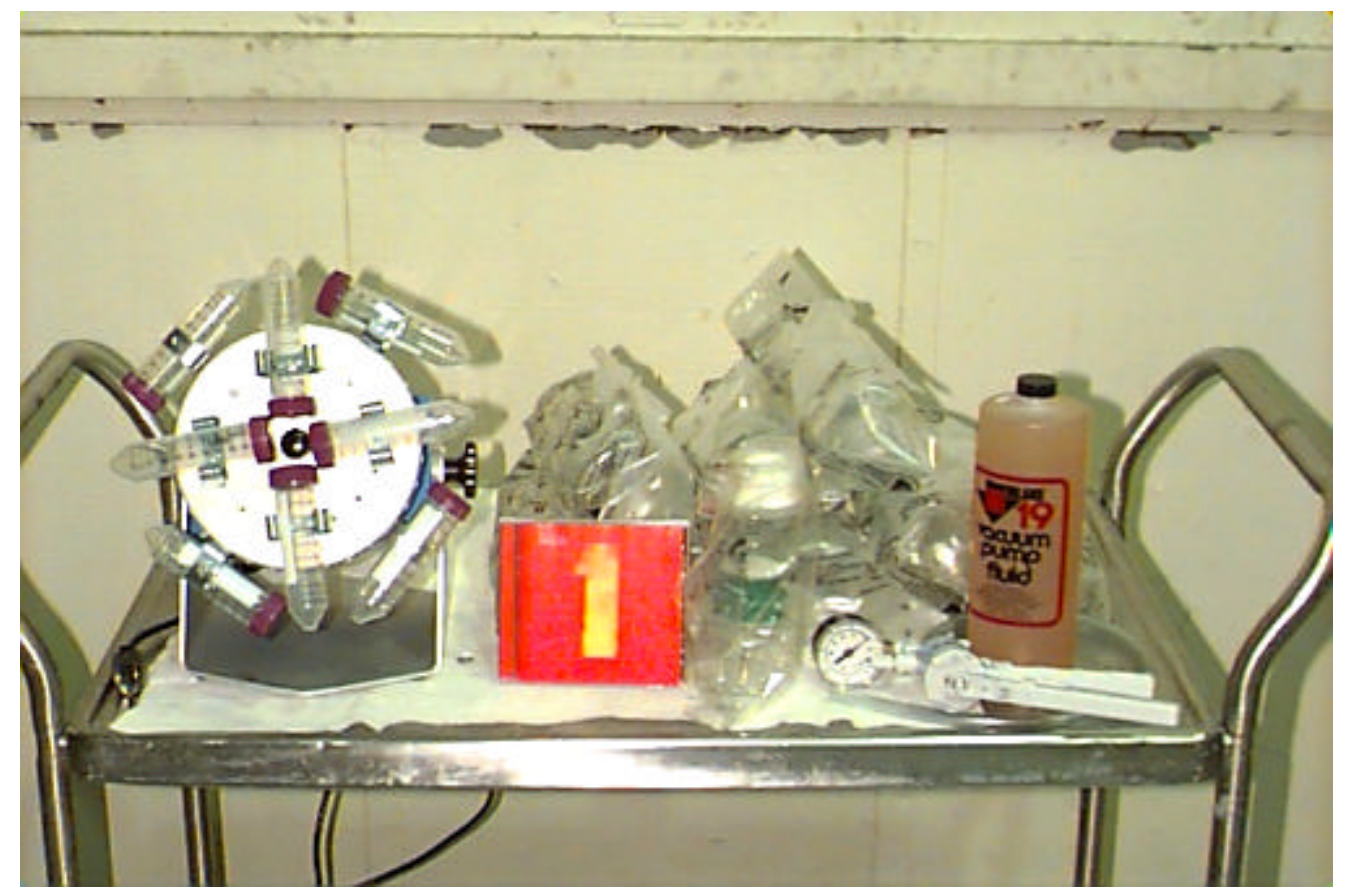

Figure 1. Equipment used for contacting oil and propyl phosphonate SAMMS. The equipment was provided to RFETS from Oak Ridg e National Laboratory. A music CD and a 1-L container of oil are also shown for comparison purposes.

\section{Results and Discussion}

The proposed treatment was easily implemented on the laboratory scale. It was noted that the SAMMS material was initially slightly difficult to disperse but it became dispersed after vigorous hand shaking. Two sets of experiments were conducted using various SAMMS-to-oil ratios. The results from the analysis are shown in Table 1. In general, more of the radionuclides were removed in the experiments conducted with higher SAMMS-to-oil ratios. The same information is also displayed in Figure 2 for the two main contaminants ( $\mathrm{Pu}$ and $\mathrm{U})$. As is noted, with the exception of one data point, the data showed that adding more than $10 \mathrm{~g} / \mathrm{L}$ of SAMMS did not result in improved removal efficiency. The radionuclide loading on the SAMMS material at this point was $3.8 \mathrm{~g} \mathrm{Pu} / \mathrm{kg}$ and $14 \mathrm{~g} \mathrm{U} / \mathrm{kg}$. The calculated adsorption distribution coefficients [radionuclide loading (in $\mathrm{g} / \mathrm{kg}$ ) divided by final liquid radionuclide concentration (in $\mathrm{g} / \mathrm{L}$ )] were 790 and $280 \mathrm{~L} / \mathrm{kg}$ for Pu and U, respectively. This was well below the expected values but clearly show the potential for $\mathrm{Pu}$ and $\mathrm{U}$ removal from oils. It is quite possible that a fraction of $\mathrm{Pu}$ and $\mathrm{U}$ in this particular oil is in a chemical form not targeted by the SAMMS material. This would explain why the capacity was less than expected. 


\begin{tabular}{cccc}
\hline $\begin{array}{c}\text { Amount SAMMS per } \\
\mathbf{5 0} \mathbf{~ m L} \text { of oil }(\mathbf{g})\end{array}$ & \multicolumn{3}{c}{ Radionuclide concentration in the filtrate $(\mathbf{g} / \mathbf{L})$} \\
\cline { 2 - 4 } 0 & $\mathbf{P u}$ & $\mathbf{U}$ & $\mathbf{A m}$ \\
\hline & 0.0433 & 0.193 & $1.66 \cdot 10^{-6}$ \\
0.047 & 0.0375 & 0.157 & $1.57 \cdot 10^{-6}$ \\
0.104 & 0.0345 & 0.136 & $1.57 \cdot 10^{-6}$ \\
0.198 & 0.0214 & 0.110 & $1.47 \cdot 10^{-6}$ \\
0.354 & 0.00869 & 0.0713 & $1.40 \cdot 10^{-6}$ \\
0.500 & 0.00489 & 0.0504 & $1.09 \cdot 10^{-6}$ \\
& & Experiment & \\
0.650 & 0.0101 & 0.00143 & $1.01 \cdot 10^{-6}$ \\
0.810 & 0.0112 & 0.0420 & $7.61 \cdot 10^{-7}$ \\
1.001 & 0.00959 & 0.0685 & $6.39 \cdot 10^{-7}$ \\
1.200 & 0.00545 & 0.0301 & $5.57 \cdot 10^{-7}$ \\
\hline
\end{tabular}

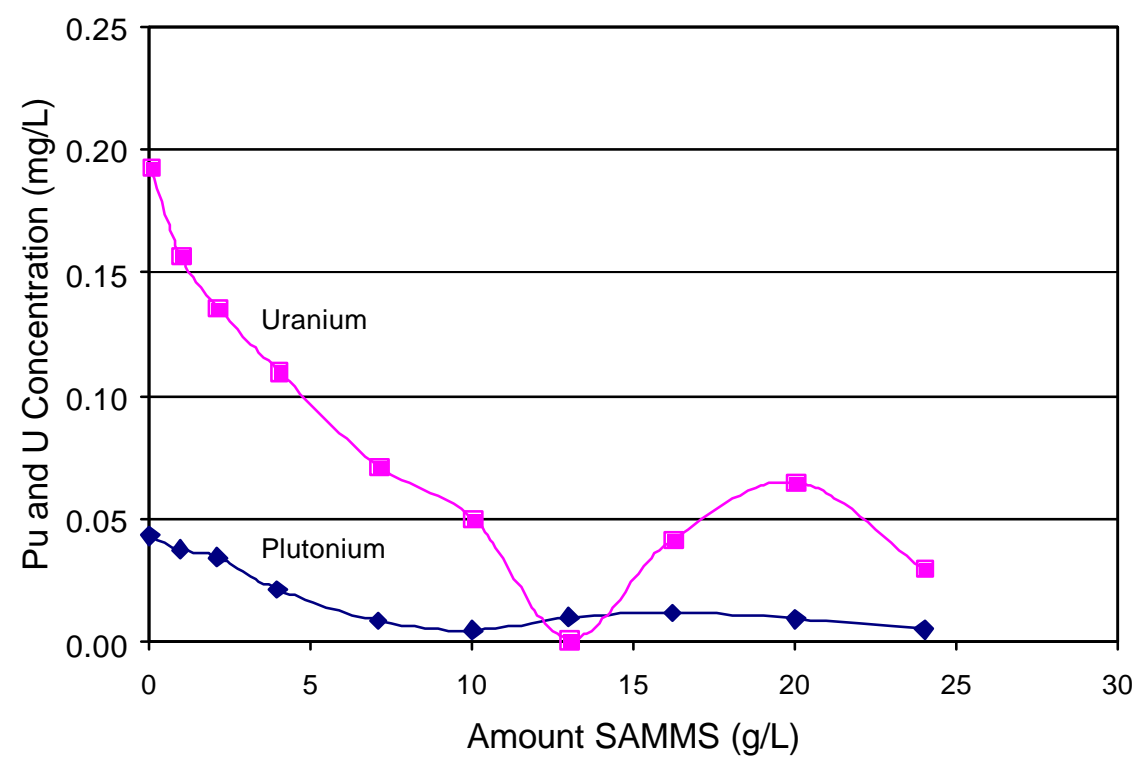

Figure 2. Concentration of plutonium and uranium in treated oil as a function of SAMMS addition. (The data point collected at $13 \mathrm{~g}$ SAMMS/L is most likely erroneous in the $\mathrm{U}$ analysis.)

\section{Conclusions}

The results demonstrate that the stabilization agent propyl phosphonate SAMMS can attract plutonium, uranium, and americium in oil. The radionuclide-laden material can then be removed via filtration. The capacity of the 
SAMMS material was lower than expected from the earlier experiments conducted at PNNL. The technology is nevertheless promising, showing the potential for adsorption of actinides from oils .

\section{References}

1. Liu, J., G.E. Fryxell, S.V. Mattigod, M. Gong, Z. Nie, X. Feng, K.N. Raymond, "Self-Assembled Monolayers on Mesoporous Support (SAMMS) Technolgy for Contaminant Removal and Stablization, Pacific Northwest National Laboratory, PNNL-12006, (September 1998).

2. Feng, X., J. Liu, G.E. Fryxell, M. Gong, L. -Q. Wang, X. Chen, D.E. Kurath, C.S. Ghormley, K.T. Klasson, and K.M. Kemner, "Self-Assembled Mercaptan on Mesoporous Silica (SAMMS) Technology for Mercury Removal and Stabilization,” Pacific Northwest National Laboratory, PNNL-11691, (September 1997).

3. Klasson, K.T., P.A. Taylor, R.L. Cummins, and B.S. Evans, "Removal of Mercury and Tritium from DOE Waste Oils," Oak Ridge National Laboratory, ORNL/TM-13751, (March 1999). 